\section{Commentary: What is behind the door to unloadling?}

\author{
Donald D. Glower, MD
}

Goodwin and Selzman ${ }^{1}$ provide an excellent review of 60 years of research examining interventions to shorten the time to ventricular unloading (ie, door to unloading [DTU]) after myocardial ischemic injury. The authors suggest that DTU may have an important but unrealized role in minimizing myocardial ischemia-reperfusion injury, perhaps as has been achieved with door to balloon time protocols. ${ }^{2}$ The authors also make the case that cardiac surgeons may have a role in DTU therapies, whether during coronary bypass grafting or with mechanical circulatory support (MCS).

Several important questions remain regarding DTU, despite 60 years of research. First, what is the best way to achieve DTU? An important clinical pilot study using the Impella device (Abiomed, Danvers, Mass) before percutaneous coronary reperfusion failed to show clinical benefit. ${ }^{3}$ Is there a role for more aggressive but potentially more morbid means of MCS such as extracorporeal membrane oxygenation (ECMO) or TandemHeart (LivaNova PLC, London, United Kingdom)? Given the morbidity and expense of ECMO and TandemHeart, the answer here may be situation dependent.

Second, what specific clinical situations can significantly benefit from DTU? The authors point out that, even outside the setting of myocardial infarction, routine coronary bypass grafting involves reperfusion injury and could benefit from DTU. However, if the potential benefit in this setting was significant, one would expect that off-pump coronary bypass grafting would be harmful, when in fact it generally is not. ${ }^{4}$ Based on available data, MCS might

\footnotetext{
From the Division of Cardiothoracic Surgery, Department of Surgery, Duke University Medical Center, Durham, NC.

Disclosures: The author reported no conflicts of interest.

The Journal policy requires editors and reviewers to disclose conflicts of interest and to decline handling or reviewing manuscripts for which they may have a conflict of interest. The editors and reviewers of this article have no conflicts of interest.

Received for publication July 9, 2020; revisions received July 9, 2020; accepted for publication July 10, 2020; available ahead of print July 15, 2020.

Address for reprints: Donald D. Glower, MD, Division of Cardiothoracic Surgery, Department of Surgery, Duke University Medical Center, Box 3851, Durham, NC 27710 (E-mail: Glowe001@mc.duke.edu).

J Thorac Cardiovasc Surg 2021;161:2051-2

$0022-5223 / \$ 36.00$

Copyright (C) 2020 by The American Association for Thoracic Surgery

https://doi.org/10.1016/j.jtcvs.2020.07.037
}

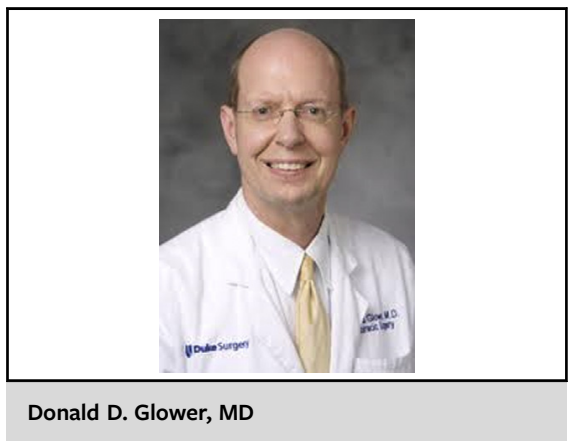

CENTRAL MESSAGE

Mechanical circulatory support

may provide new opportunities

for cardiac surgeon to use left

ventricular unloading to limit

ischemia-reperfusion injury in

myocardial infarction.

have the most benefit as a DTU therapy in acute coronary ischemia associated with cardiogenic shock. However, to date, most trials of MCS in settings of cardiogenic shock have focused on patient survival, with little insight into myocardial reperfusion injury. ${ }^{5}$

Third, just how much clinical benefit can be obtained from DTU once the ischemic event has occurred, and is that benefit worth the clinical risk of intervention? Most studies to date have shown relatively small improvements in ventricular function and infarct size from unloading interventions. ${ }^{6}$ Decreasing the door to balloon time may therefore be much more powerful than DTU interventions. Nonetheless, DTU may be more logistically manageable than door to balloon time, which occurs largely outside health care settings.

The fact that 60 years of investigation have not answered these questions suggests that the answers may not be easy to find. Recent advances in percutaneous and surgical MCS (eg, Impella, TandemHeart, and ECMO) do open up interventions not previously investigated. DTU investigations using TandemHeart or ECMO will be opportunities uniquely suited to cardiac surgeons. There is clearly much work to be done to identify exactly what potential gain hides behind the door.

\section{References}

1. Goodwin ML, Selzman CH. Take a load off: unloading and reperfusion. J Thorac Cardiovasc Surg. 2021;161:2046-50. 
2. Foo CY, Bonsu KO, Nallamothu BK, Reid CM, Dhippayom T, Reidpath DD, et al. Coronary intervention door-to-balloon time and outcomes in ST-elevation myocardial infarction: a meta-analysis. Heart. 2018;104:1362-9.

3. Kapur NK, Alkhouli MA, DeMartini TJ, Faraz H, George ZH, Goodwin MJ, et al. Unloading the left ventricle before reperfusion in patients with anterior STsegment-elevation myocardial infarction. Circulation. 2019;139:337-46.

4. Guan Z, Guan X, Gu K, Lin X, Lin J, Zhou W, et al. Short-term outcomes of on- vs off-pump coronary artery bypass grafting in patients with left ventricular dysfunction: a systematic review and meta-analysis. J Cardiothorac Surg. 2020;15:84-96.
5. Ouweneel DM, Schotborgh JV, Limpens J, Sjauw KD, Engström AE Lagrand WK, et al. Extracorporeal life support during cardiac arrest and cardiogenic shock: a systematic review and meta-analysis. Intensive Care Med. 2016; 42:1922-34.

6. Saku K, Kakino T, Arimura T, Sunagawa G, Nishikawa T, Sakamoto T, et al. Left ventricular mechanical unloading by total support of Impella in myocardial infarction reduces infarct size, preserves left ventricular function, and prevents subsequent heart failure in dogs. Circ Heart Fail. 2018; 11:e004397.
See Article page 2046.

\section{Commentary: "The weight" will be worth it: Avoiding premature judgment on the success or failure of left ventricular unloading in mitigating reperfusion injury}

\author{
Michael I. Brener, MD, ${ }^{\mathrm{a}}$ and \\ Daniel Burkhoff, MD, PhD ${ }^{\mathrm{a}, \mathrm{b}}$
}

Mortality following acute myocardial infarction (AMI) has declined substantially with the advent of primary reperfusion therapy, but the incidence of new-onset heart failure remains stubbornly high. A long list of therapies and treatment paradigms like ischemic preconditioning and novel pharmacology showed promise in preclinical models but have failed to reduce infarct size in clinical trials. In this issue of the Journal, Goodwin and Selzman ${ }^{1}$ rigorously describe the recent literature surrounding left ventricular (LV) unloading and its innovative application to mitigate reperfusion injury following AMI.

Preclinical models of LV unloading with a transvalvular axial flow pump like the Impella family of devices (Abiomed Inc, Danvers, Mass) have shown compelling

From the a Division of Cardiology, Columbia University Medical Center-NewYork Presbyterian Hospital; and ${ }^{\mathrm{b}}$ Cardiovascular Research Foundation, New York, NY.

Disclosures: Dr Burkhoff reports consulting for IMPULSE Dynamics and institutional grant support from Ancora Medical; Dr Brener reported no conflicts of interest.

The Journal policy requires editors and reviewers to disclose conflicts of interest and to decline handling or reviewing manuscripts for which they may have a conflict of interest. The editors and reviewers of this article have no conflicts of interest.

Received for publication July 27, 2020; revisions received July 27, 2020; accepted for publication Aug 17, 2020; available ahead of print Aug 21, 2020.

Address for reprints: Michael I. Brener, MD, Cardiovascular Medicine, Presbyterian Hospital, 622 West 168th St, Floor 3, Room 347, New York, NY 10032 (E-mail: mib2102@cumc.columbia.edu).

J Thorac Cardiovasc Surg 2021;161:2052-3

$0022-5223 / \$ 36.00$

Copyright (c) 2020 by The American Association for Thoracic Surgery

https://doi.org/10.1016/j.jtcvs.2020.08.041

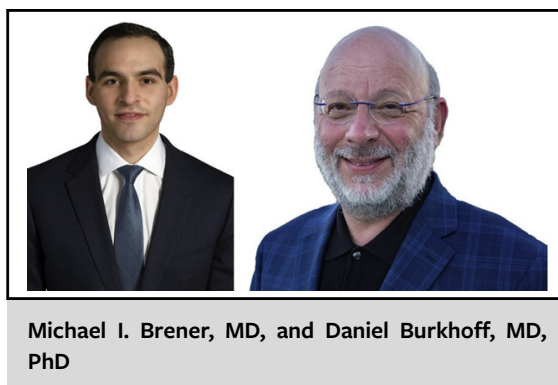

CENTRAL MESSAGE

LV unloading has the potential to

limit injury associated with

myocardial infarction and reper-

fusion therapies. More work re-

mains to translate these benefits

from the bench to the bedside.

results with respect to reperfusion injury. Recently, Esposito and colleagues ${ }^{2}$ demonstrated activation of a cardioprotective cascade led by the signaling protein stromal-derived factor- $1 \alpha$ in a swine model where reperfusion was delayed for at least 30 minutes after unloading with an Impella device. These findings provide a mechanistic explanation for the improved ventricular performance observed in previous large animal studies. Smalling and colleagues ${ }^{3}$ almost 3 decades ago and Meyns and colleagues ${ }^{4}$ almost 2 decades ago showed that an axial flow device significantly reduced ventricular filling pressures and infarct size when applied during ischemia before reperfusion. These improvements correlated with decreases in myocardial oxygen consumption created by unloading. ${ }^{4}$ However, Goodwin and Selzman astutely remind us that ischemic time cannot be controlled as it can in the preclinical setting, and that animal models fail to replicate the mix of comorbidities shared by 